\title{
RANCANG BANGUN PARTICULATE REDUCER SEBAGAI UPAYA MENGURANGI EMISI GAS BUANG PADA KERETA INSPEKSI
}

\author{
Sesoca Caesar T.J. \\ Fadli Rozaq \\ Hari Boedi \\ Teknologi Mekanika Perkeretaapian Teknologi Mekanika Perkeretaapian Teknologi Mekanika Perkeretaapian \\ Politeknik Perkeretaapian Indonesia Politeknik Perkeretaapian Indonesia Politeknik Perkeretaapian Indonesia \\ Jln. Tirta Raya I \\ Madiun (63129) \\ Jln. Tirta Raya I \\ Madiun (63129) \\ Jln. Tirta Raya I \\ Madiun (63129) \\ sesoca.tmp1741@taruna.api.ac.id \\ fadli@pengajar.ppi.ac.id \\ hariboedi@ppi.ac.id
}

\begin{abstract}
Air pollution is a process that causes changes in the composition of air from normal conditions, resulting in changes in air temperature. Air pollution is not only bad for health, but also has a negative impact on the environment. Currently, the Indonesian Railways Polytechnic has an Inspection Train which is not equipped with a device capable of reducing exhaust emissions. In this study, a particulate reducer was designed to reduce exhaust emissions on the Inspection Train. Furthermore, the design results were tested on the Inspection train, using 3 types of diesel fuel, namely Pertamina Dex, Dexlite, and Biosolar. This study shows that the particulate reducer designed in this study can significantly reduce emissions, namely $23.9 \%$ for Pertamina Dex fuel, $17.9 \%$ for Dexlite fuel, and $10.6 \%$ for Biosolar fuel.
\end{abstract}

Keywords: particulate reducer; air pollution; air temperature; diesel fuel.

\begin{abstract}
Abstrak
Pencemaran udara adalah suatu proses yang menyebabkan terjadinya perubahan pada komposisi udara dari keadaan normal, sehingga mengakibatkan temperatur udara berubah. Pencemaran udara ini tidak hanya berakibat buruk terhadap kesehatan, namun juga berdampak buruk terhadap lingkungan. Saat ini Politeknik Perkeretaapian Indonesia memiliki Kereta Inspeksi yang belum dilengkapi dengan alat yang mampu mereduksi emisi gas buang. Pada studi ini dilakukan rancang bangun suatu particulate reducer, untuk mengurangi emisi gas buang pada Kereta Inspeksi tersebut. Selanjutnya hasil rancangan diuji-coba pada kereta Inspeksi, dengan menggunakan 3 jenis bahan bakar diesel, yaitu Pertamina Dex, Dexlite, dan Biosolar. Hasil pengujian menunjukkan bahwa particulate reducer yang dirancang pada studi ini dapat mengurangi emisi secara signifikan, yaitu 23,9\% untuk bahan bakar jenis Pertamina Dex, 17,9\% untuk bahan bakar jenis Dexlite, dan $10,6 \%$ untuk bahan bakar jenis Biosolar.
\end{abstract}

Kata-kata kunci: particulate reducer; pencemaran udara; temperatur udara; bahan bakar diesel.

\section{PENDAHULUAN}

Mesin diesel atau yang lebih dikenal dengan nama Internal Combustion Engine menghasilkan tenaga mekanik yang berasal dari perubahan tenaga kimia pada bahan bakar yang terjadi di dalam ruang bakar dengan langkah kompresi (Wahjono dan Rozaq, 2018). Mesin diesel yang digunakan sebagai penggerak memiliki keunggulan, seperti keandalannya, pemanfaatan pembakaran pada bahan bakar yang tinggi, dan dapat dimanfaatkan untuk dijadikan angkutan beban berat. Tetapi mesin diesel ini mempunyai kelemahan, yaitu pada 
gas buang yang dihasilkan dari pembakaran yang tinggi, sehingga dapat merugikan lingkungan (Bagas, 2013). Irawan et al. (2013) menyatakan bahwa meningkatnya emisi gas buang yang signifikan pada sektor transportasi menyebabkan dampak negatif terhadap lingkungan, bahkan terhadap kehidupan. Polutan yang dihasilkan oleh kendaraan, berupa gas hidrokarbon, mengakibatkan terjadinya kabut campuran asap atau smog (Kusuma, 2010) dan gas karbon monoksida (CO), yang bersifat tidak berwarna, tidak berbau, dan tidak berasa tetapi bersifat beracun, yang mengakibatkan gangguan dalam hemoglobin (Havendri, 2008). Mesin diesel menghasilkan karbon dioksida yang lebih kecil dibandingkan dengan mesin bensin. Karbon dioksida ini berbentuk gas atau padat, bergantung pada tekanan dan temperatur, serta bersifat oksida asam, tidak memiliki warna, dan tidak berbau, yang dapat menyebabkan terjadinya asidosis akibat kadar asam terlalu tinggi pada sistem pernapasan, menurunnya kontraksi jantung, meningkatkan denyut nadi dan tekanan darah, hingga menyebabkan kematian (Subekti, 2009).

Pengujian lokomotif berpenggerak nonlistrik, dengan penggerak mesin diesel, oleh Balai Pengujian Perkeretaapian menyatakan bahwa jumlah kandungan karbon monoksida adalah sebesar 4000 ppm. Meskipun jumlah tersebut lebih rendah daripada ketentuan yang ada, yaitu 5000 ppm, jika masalah tersebut tidak diimbangi oleh upaya pencegahan, akan dihasilkan dampak negatif terhadap udara ambien, sehingga udara ambien tersebut tidak dapat bekerja maksimal sesuai dengan fungsinya.

Saat ini pemerintah telah mengatur dalam KM Lingkungan Hidup Nomor 5 Tahun 2006, mengenai kandungan atau polutan yang diizinkan keluar dari muffler pada kendaraan. Pemerintah juga telah mengatur polutan di udara, melalui Peraturan Pemerintah Nomor 41 Tahun 1999, Pengendalian Pencemaran Udara. Sebagai upaya untuk mendukung program Pemerintah, sesuai dengan ketentuan pada UU Nomor 32 Tahun 2009, tentang Perlindungan dan Pengelolaan Lingkungan Hidup, diperlukan inovasi baru untuk menangani masalah emisi.

Particulate reducer atau catalytic converter (CC) merupakan sebuah media yang berfungsi untuk mengontrol emisi gas buang, yang diletakkan setelah exhaust manifold (Irawan et al., 2013). Proses reduksi emisi dipengaruhi oleh gas buang yang mengenai permukaan particulate reducer (Mokhtar, 2014).

Politeknik Perkeretaapian Indonesia saat ini memiliki sarana perkeretaapian berupa Kereta Inspeksi (KAIS), seperti yang ditunjukkan pada Gambar 1. Namun KAIS ini belum dilengkapi dengan alat yang mampu mereduksi emisi, yang berguna untuk mengurangi opasitas gas buang KAIS.

Pada penelitian ini dilakukan pengumpulan data primer dan data sekunder. Data primer adalah data yang didapat langsung di lapangan, berupa tingkat opasitas yang dikeluarkan tanpa alat. Proses pembuatan desain, produksi, serta pengujian tingkat opasitas dilakukan di Workshop Politeknik Perkeretaapian Indonesia. Data sekunder didapat dari referensi, berupa jurnal, buku, serta informasi yang terdapat di internet. 


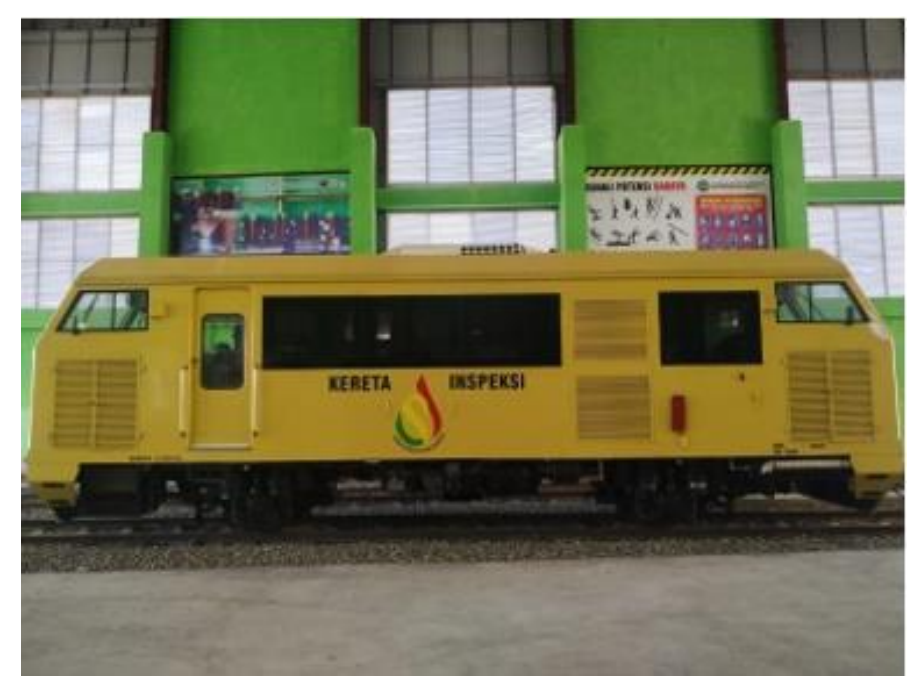

Gambar 1 Kereta Inspeksi

\section{PROSES PRODUKSI}

Proses produksi particulate reducer melalui beberapa tahapan, yaitu perencanaan, perancangan, pembuatan alat, dan pengujian. Pembuatan particulate reducer ini dimulai dengan membuat desain katalisator menggunakan perangkat lunak Solidworks 2017, kemudian dilanjutkan dengan pembuatan katalisator dan casing.

\section{Perancangan}

Pada proses perancangan atau proses desain katalisator, digunakan 2 bentuk katalis yang berbeda, yaitu menyerupai turbin pesawat udara dan menyerupai jaring laba-laba (lihat Gambar 2). Desain yang menyerupai turbin pesawat udara dibuat dari pelat tembaga dengan tinggi $40 \mathrm{~cm}$ dan tebal $1 \mathrm{~mm}$, lalu pelat tembaga tersebut dibengkokkan sehingga menyerupai turbin pesawat udara. Desain yang menyerupai jaring laba-laba dibuat dengan 2 bentuk yang berbeda, yaitu melingkar sebanyak 5 serta arah vertikal dan arah horizontal sebanyak 32. Kedua bentuk katalisator yang berbeda ini memiliki diameter 9 inch.
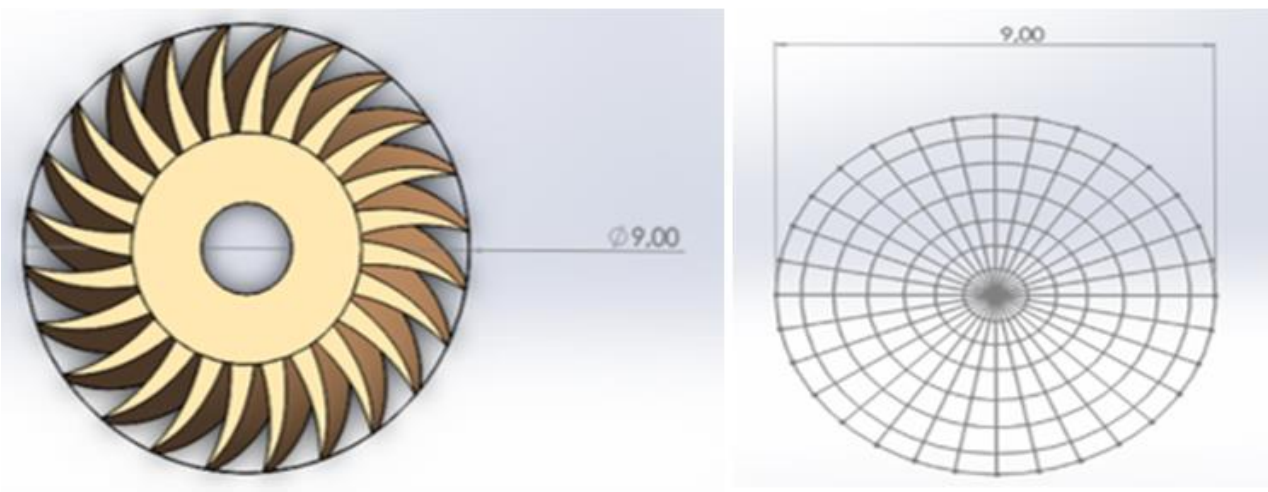

Gambar 2 Desain Katalisator Menyerupai Baling-Baling Pesawat Udara (Kiri) dan Menyerupai Jaring Laba-Laba (Kanan) 


\section{Pembuatan Alat}

Proses pembuatan particulate reducer memerlukan beberapa alat dan bahan. Alat dan bahan yang digunakan tersebut harus dipersiapkan sesuai dengan kebutuhan agar dapat menghemat biaya, tenaga, dan waktu. Material tersebut meliputi:

1) Pipa besi ukuran 3 inch dengan panjang $3 \mathrm{~m}$.

2) Pipa besi ukuran 9 inch dengan panjang $40 \mathrm{~cm}$.

3) Kawat tembaga ukuran $0,15 \mathrm{~mm}$ sebanyak $6 \mathrm{~kg}$.

4) Pelat tembaga sebanyak 2 lembar.

5) Glasswool ukuran $25 \mathrm{~cm}$ sebanyak 1 lembar.

6) Exhaust wrap ukuran 2 meter sebanyak 1 buah.

7) Clamp sebanyak 4 buah.

8) Pelat besi sebanyak 2 buah.

9) Knee sebanyak 2 buah.

10) Alat pelindung diri, yaitu rompi, safety shoes, helm pelindung, wearpack, kacamata pelindung, sarung tangan, dan earplug.

Pembuatan katalisator dimulai dengan memotong pelat tembaga yang dibuat sesuai desain (lihat Gambar 3). Pemotongan pelat tembaga dilakukan dengan menggunakan gerinda dan penggaris siku. Proses pembuatan dimulai dengan membagi ukuran pelat tembaga dengan panjang $30 \mathrm{~cm}$ dan tinggi $25 \mathrm{~cm}$, lalu dilipat menjadi 2 bagian, lalu dibentuk pada casing dan dipaku keling agar menyatu dengan casing.

Pada proses pembuatan katalisator yang menyerupai jaring laba-laba, digunakan kawat tembaga dengan tebal $0,15 \mathrm{~mm}$ sebanyak $6 \mathrm{~kg}$, yang dibentuk melingkar dan horizontal. Lingkaran jaring-jaring ini diletakkan setelah katalisator yang menyerupai baling-baling pesawat udara dengan dilapisi glasswool pada casing katalisator, dengan harapan jelaga yang tidak terbakar dapat terperangkap dalam glasswool tersebut.

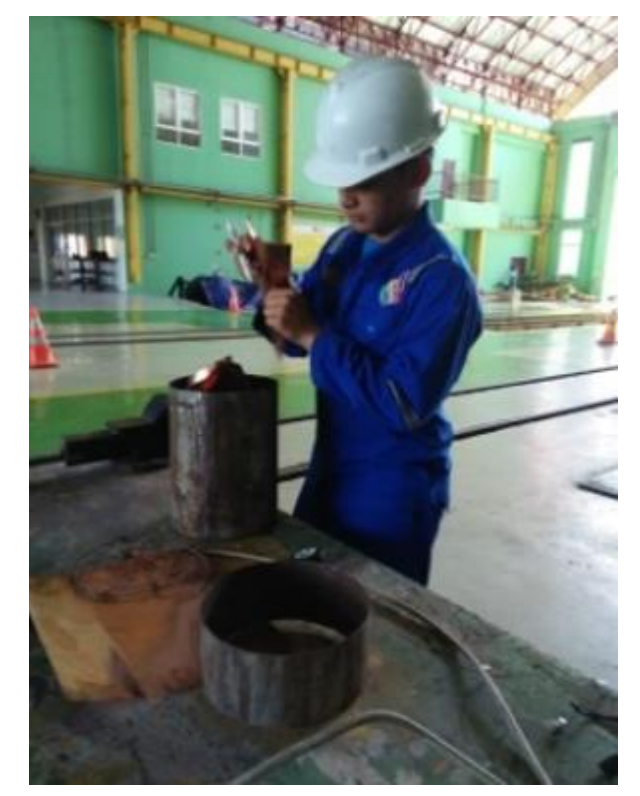

Gambar 3 Proses Pembuatan Katalisator 


\section{PROSES PENGUJIAN}

Cholifah et al. (2018) menyatakan bahwa pengujian adalah salah satu kegiatan yang terencana dan sistematis, untuk menguji dan mengevaluasi apakah hasil yang diperoleh sesuai dengan harapan. Metode pengujian yang digunakan adalah metode komparasi riset, yang merupakan metode untuk membandingkan suatu variabel atau objek penelitian dengan kondisi yang berbeda agar ditemukan perbedaan pada variabel atau objek yang diteliti. Pada penelitian ini dibandingkan tingkat kepekatan asap (opasitas) motor diesel kereta Inspeksi dengan tidak menggunakan particulate reducer dan dengan menggunakan particulate reducer.

Pengujian ini menggunakan alat diesel smoke opacity tester HD-410, dengan teknologi non dispersive infra red atau menggunakan cahaya infra merah dengan frekuensi yang telah ditentukan, yang berfungsi untuk mengukur tingkat opasitas (lihat Gambar 4). Pengujian dilakukan dengan cara memasukkan probe pada lubang knalpot. Tingkat opasitas akan terinput dalam bentuk angka. Selanjutnya hasil pengujian pada saat rpm tertinggi dicatat dan dicetak (Firman, 2014).

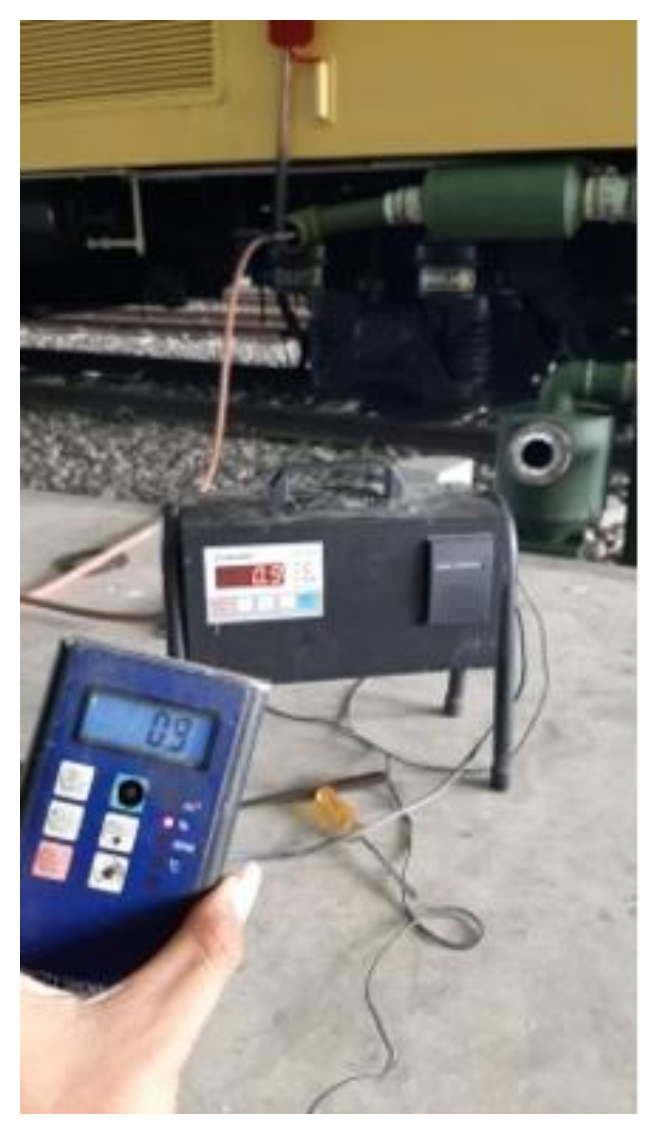

Gambar 4 Smoke Opacity Tester HD-410

Pada proses pengujian ini digunakan 3 variabel jenis bahan bakar, yaitu Biosolar, Pertamina Dex, dan Dexlite. Pengujian opasitas dilakukan selama 30 menit dengan 5 kali pengujian pada setiap variabel dan diberikan pembebanan, yaitu Air Conditioning (AC) dan 
sistem kelistrikan pada kereta api. Setelah data pengujian didapat lalu digunakan rumus untuk mengetahui penurunan opasitas, yaitu (Muktiawan, 2019):

$$
\begin{aligned}
& \text { Persentase emisi }=\frac{\text { Rata-rata emisi dengan alat }}{\text { Rata-rata emisi tanpa alat }} \times 100 \% \\
& \text { Persentase penurunan emisi }=100 \%-\text { emisi (\%) }
\end{aligned}
$$

\section{HASIL DAN PEMBAHASAN}

Hasil pengujian particulate reducer menunjukkan bahwa terjadi penurunan yang signifikan pada tingkat opasitas. Dari pengujian tingkat opasitas diperoleh hasil yang diuraikan pada bagian berikut.

\section{Penggunaan Bahan Bakar Diesel Jenis Pertamina Dex}

Hasil pengujian yang diperoleh disajikan pada Tabel 1. Dengan menggunakan Persamaan 1 dan Persamaan 2 diperoleh Persentase Emisi sebesar 76,1\% dan Persentase Penurunan Emisi sebesar 23,9\%.

Tabel 1 Hasil Pengujian BBM Pertamina Dex

\begin{tabular}{lcc}
\hline \multirow{2}{*}{ Pengujian } & \multicolumn{2}{c}{ Hasil Pengujian Emisi } \\
\cline { 2 - 3 } & Tanpa Penggunaan Alat & Penggunaan Alat \\
\hline Pengujian ke-1 & $15,3 \%$ & $13,8 \%$ \\
Pengujian ke-2 & $14,8 \%$ & $13,3 \%$ \\
Pengujian ke-3 & $14,5 \%$ & $10,9 \%$ \\
Pengujian ke-4 & $14,3 \%$ & $8,9 \%$ \\
Pengujian ke-5 & $14,0 \%$ & $8,6 \%$ \\
\hline Rata-Rata & $72,9 \%$ & $55,5 \%$ \\
\hline
\end{tabular}

\section{Penggunaan Bahan Bakar Diesel Jenis Dexlite}

Hasil pengujian yang diperoleh disajikan pada Tabel 2. Dengan menggunakan Persamaan 1 dan Persamaan 2 diperoleh Persentase Emisi sebesar 82,1\% dan Persentase Penurunan Emisi sebesar 17,9\%.

Tabel 2 Hasil Pengujian BBM Dexlite

\begin{tabular}{lcc}
\hline \multirow{2}{*}{ Pengujian } & \multicolumn{2}{c}{ Hasil Pengujian Emisi } \\
\cline { 2 - 3 } & Tanpa Penggunaan Alat & Penggunaan Alat \\
\hline Pengujian ke-1 & $18,4 \%$ & $14,7 \%$ \\
Pengujian ke-2 & $18,0 \%$ & $14,7 \%$ \\
Pengujian ke-3 & $17,5 \%$ & $14,2 \%$ \\
Pengujian ke-4 & $16,8 \%$ & $14,1 \%$ \\
Pengujian ke-5 & $16,1 \%$ & $13,6 \%$ \\
\hline Rata-rata & $86,8 \%$ & $71,3 \%$ \\
\hline
\end{tabular}

\section{Penggunaan Bahan Bakar Diesel Jenis Biosolar}

Hasil pengujian yang diperoleh disajikan pada Tabel 3. Dengan menggunakan Persamaan 1 dan Persamaan 2 diperoleh Persentase Emisi sebesar 89,4\% dan Persentase Penurunan Emisi sebesar 10,6\%. 
Tabel 3 Hasil Pengujian BBM Biosolar

\begin{tabular}{ccc}
\hline \multirow{2}{*}{ Pengujian } & \multicolumn{2}{c}{ Hasil Pengujian } \\
\cline { 2 - 3 } & Tanpa Penggunaan Alat & Penggunaan Alat \\
\hline Pengujian ke-1 & $14,6 \%$ & $12,7 \%$ \\
Pengujian ke-2 & $13,8 \%$ & $12,5 \%$ \\
Pengujian ke-3 & $13,7 \%$ & $12,4 \%$ \\
Pengujian ke-4 & $13,7 \%$ & $12,3 \%$ \\
Pengujian ke-5 & $13,6 \%$ & $12,2 \%$ \\
\hline Rata-rata & $58,52 \%$ & $52,34 \%$ \\
\hline
\end{tabular}

\section{KESIMPULAN}

Pembuatan particulate reducer pada penelitian ini menggunakan 2 jenis model katalisator dan menggunakan tembaga sebagai katalisator. Model-model katalisator yang digunakan adalah model yang menyerupai turbin pesawat udara dan model yang menyerupai jaring laba-laba, sehingga particulate dapat terperangkap pada glasswool.

Penggunaan alat ini mampu menurunkan secara signifikan emisi gas buang pada mesin diesel Kereta Inspeksi PPI. Dibandingkan alat yang standar atau tanpa penggunaan alat, terjadi penurunan emisi sebesar 23,9\% pada bahan bakar jenis Pertamina Dex, 17,9\% pada bahan bakar jenis Dexlite, dan 10,6\% pada bahan bakar jenis Biosolar.

\section{UCAPAN TERIMA KASIH}

Penulis mengucapkan terima kasih kepada seluruh civitas akademika Politeknik Perkeretaapian Indonesia yang telah membantu dalam proses penyelesaian penelitian.

\section{DAFTAR PUSTAKA}

Bagas, R. 2013. Menipisnya Cadangan Bahan Bakar Fosil dan Meningkatnya Polusi Udara yang Mengakibatkan Pemanasan Global Terjadi karena Adanya Peningkatan Jumlah Kendaraan. Tesis tidak diterbitkan. Semarang: Program Pascasarjana, Universitas Diponegoro.

Cholifah, W.N., Yulianingsih, dan Sagita, S.M. 2018. Pengujian Black Box Testing pada Aplikasi Action dan Strategy Berbasis Android dengan Teknologi Phonegap. STRING (Satuan Tulisan Riset dan Inovasi Teknologi), 3 (2): 206.

Firman, H. 2014. Perencanaan Pemeliharaan dan Perawatan Peralatan Pengujian Kendaraan Bermotor. Skripsi (tidak dipublikasikan). Padang: Universitas Bung Hatta. Havendri, A. 2008. Kaji Eksperimental Perbandingan Prestasi dan Emisi Gas Buang Motor Diesel menggunakan Bahan Bakar Campuran Solar. TeknikA, 1 (29): 38-46. 
Irawan, B. 2012. Rancangan Bangun Catalytic Converter Material Substrat Tembaga Berlapis Mangan untuk Mereduksi Gas Karbon Monoksida Motor Bensin. Seminar HasilHasil Penelitian LPPM UNISMUS, hlm. 1-14. Semarang.

Irawan, R.M.B., Purwanto, dan Hadiyanto. 2013. Karakterisasi Katalis Tembaga pada Catalytic Converter untuk Mengurangi Emisi Gas Carbon Monoksida Motor Bensin. Traksi, 13 (2): 52-62.

Kusuma, I.G.B.W. 2010. Alat Penurun Emisi Gas Buang pada Motor, Mobil, Motor Tempel, dan Mesin Pembakaran Tak Bergerak. MAKARA of Technology, Series 6 (3): 95101.

Mokhtar, A. 2014. Catalityc Converter Jenis Katalis Pelat Tembaga Berbentuk Sarang Lebah untuk Mengurangi Emisi Kendaraan Bermotor. Jurnal Gamma, 10 (1): 104-108.

Muktiawan, A.K. 2019. Catalictic Converter Jenis Katalis Pelat Kuningan. Tugas Akhir tidak diterbitkan. Malang: Jurusan Teknik Mesin, Universitas Muhammadiyah Malang.

Subekti, P. 2009. Pengaruh Penggunaan Media Penyerap Gas Buang Pada Alat Pengendali Pencemaran Udara untuk Kendaraan Bermesin Diesel. Jurnal APTEK, 1 (1): 1-11.

Wahjono, H.B. dan Rozaq, F. 2018. Perbandingan Penggunaan Bahan Bakar High Speed Diesel dan Bio Solar terhadap Emisi Gas Buang. Jurnal Perkeretaapian Indonesia, 2 (1): 47-55. 